\title{
On-line Education Techniques during Lockdown- A Review
}

\author{
Khalid Alfatmi \\ Assistant Professor \\ Department of Computer \\ Engineering \\ SVKM'S Institute of Technology, \\ Dhule
}

\author{
Mayuri Kulkarni \\ Assistant Professor \\ Department of Computer \\ Engineering \\ SVKM'S Institute of Technology, \\ Dhule
}

\author{
Tukaram Gawali \\ Assistant Professor \\ Department of Computer \\ Engineerin \\ SVKM'S Institute of Technology, \\ Dhule
}

\begin{abstract}
The world is going through a pandemic of COVID-19. Due to this most of the countries have entered a lockdown. The lockdown has affected the overall economy. The education sector is not left either. But due to technology and the internet as key player, there are number of ways the instructors and students come forward to continue with education from home in the form of online teaching learning. This situation is going to persist for more months to come hence we will be depending on online education system for a longer time. In this paper we present a survey of different platforms that are available for conducting on-line lectures as well as conducting tests and assignments; during lockdown. This paper will provide a brief knowledge of platforms- Zoom, MS-Team, Cisco Webex, Google classroom, Youtube Live etc.; which will make awareness about the different options available for online teaching-learning as well as it may help one to decide what to choose.
\end{abstract}

\section{Keywords}

COVID-19, Lockdown, online learning, Survey

\section{INTRODUCTION}

The year 2020 will be remembered in history for mainly the pandemic of COVID-19. But it will also be remembered for the biggest revolution in education sector when all of a sudden the world moved towards online education from the age old classroom teaching. Due to lockdown all students are stuck at homes and cannot attend the classes. Also the lockdown is lengthy and the academic year is running out to complete the syllabus. As the education system works, we cannot delay the processes for much longer and hence there is a need to proceed with the education sitting at home. Slow but steady the instructors as well as students along with parents moved towards the use of online teaching learning tools.

Universities and colleges all over the world moved towards online lectures and classes to continue with the academics and restricting with social distancing. The major role played over here is by internet and the technology in hand, in most cases cell phones. As data rates being quite affordable and almost every individual having a mobile phone, this way of education was the best option. To accomplish the task universities started using video conferencing applications to conduct online classes such as Zoom, Webex, Skype. Some preferred to post recorded videos on Youtube as well as on Government e-learning portals such as SWAYAM. Also most of the organizations held live lectures using YouTube live sessions as well as Faceook Live. The testing and evaluation of students can be done using the Learning Management System (LMS) platform such as Moodle, Google classroom etc. Some specific platforms have integrated functionality of Video conferencing as well as testing and evaluation of students such as MS Team. In most areas where the awareness of these applications is not there, Whatsapp was used for the said purpose.

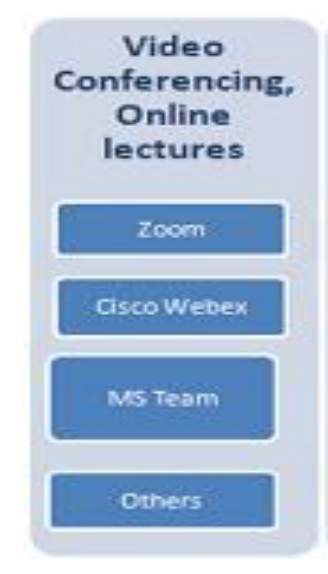

\section{LITERATURE SURVEY}

As the education institutes have moved towards using the online platforms, here we make clear the difference between online learning and online education; then we discuss the
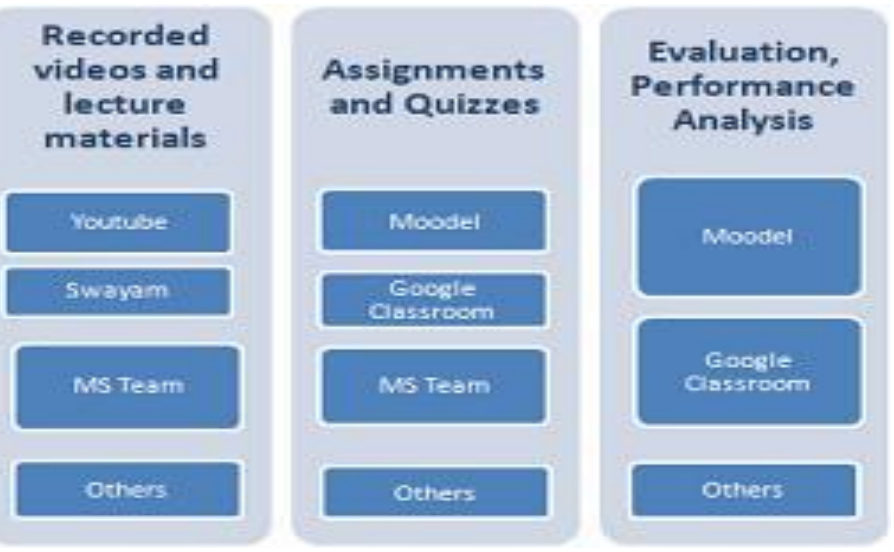

Fig 1: Online Education Techniques challenges in online education and finally we elaborate the various techniques that are being used widely for conducting education online. 


\subsection{Online learning vs. Online education system}

There is a difference between online learning and the online education system. Both have shown tremendous increase in the COVID-19 lockdown. Online learning provides people with the opportunity to gain new skills through education based on internet. The course is made up of instructor videos; mostly in recorded form combined with quizzes, assignments or projects. It provides certification course ranging from one week to several months, which can be helpful for an individual in an ongoing project, promotion or switch to a new job profile or it can be just for the pleasure of learning a new thing. Even before the pandemic, Research and Markets forecasts the online education market as $\$ 350$ Billion by 2025 [8]. Poplar examples of online learning are Coursera, Udemy, edx, Swayam. Almost all of them are chargeable platforms, but during the pandemic most have floated free of cost courses. Online education system is the traditional classroom teaching shifted to online mode. Here the instructor meets the class as per the time table and delivers a lecture using a video conferencing tool. Live lecture helps students to clear their doubts immediately. He can also upload the recorded video on YouTube or an LMS platform. The instructor also evaluates the students using the options available in LMS such as assignments and quizzes. Following are the building blocks of Online education system: Video Conferencing based Online lectures, Recorded Videos and Lecture Material, Assignments and Quizzes and Evaluation and Performance Analysis.

\subsection{Challenges of online education system}

There are various challenges in online education system, some of which we have tried to list out below. Selecting the proper platform is the first and most important. Some challenges are related to online lecture conduction and attendance; other deals with evaluation and performance analysis.

\subsubsection{Awareness of the available platforms}

Technical institution can decide what type of various platforms available and which one is better to use. Also the student and staff at such institutions are comfortable using these applications. But in non-technical institutions many students and faculty find it difficult to adapt to the new technologies. Also they may end up with some application which does not serve the part completely. There are lot of open source and free of cost options available which one should be aware of. Otherwise some institutions will end up purchasing an application with load of functionalities which will rarely be used even if an alternative light weight app is available on the internet free of cost.

\subsubsection{Availability of Resources}

Pursuing education online need some basic resource such as internet connectivity and a device such as laptop, desktop or smart phone. In most of the cases poor internet connectivity is the major issue whereas in other cases the devices are not readily available. Also data pack charges for the internet can also be an issue for some economical weaker section person. To save bandwidth the video sharing can be turned off by the audience which can solve the low bandwidth issue to some extent. The user experience of the application also differs based on the type of device being used i.e. while submitting assignments using the application on Laptop or desktop gives an enhance exposure as compared to smart phones.

\subsubsection{Monitoring}

Monitoring the audience is the second challenge in conduction of online class. As the students are away and of course you cannot see their activities- whether they are physically present in the lecture. But some apps give you indicators in the audience section which uses various colour options to show the status of the participants whether they are active or inactive. Also the idea of cross questioning and conducting poll in between the lecture can arouse the sense of attentivity among students.

\subsubsection{Consistency}

Using online platform the instructor need to well prepared always. Also the resource with the instructor should work without any flaws. This builds consistency in the online lectures. If in case the instructor is not well prepared with the material he is going to talk about, then its very difficult to bind together the audience in the online lecture. Similarly due to technical flaw at the students side, he/she will not be able to understand the lecture which again causes the student to lose interest.

\subsubsection{Evaluation}

As we are dealing with students online, the way of evaluation has also changed. Here you need to create quizzes and assignments and assign it to the students to solve in a stipulated time. But monitoring the students as done during a class test is not possible. This forms another challenge in online education. The instructor may think of various ways to evaluate the students online, some can be by using unsolved questions or conducting an open book test.

\subsection{Video Conferencing Applications}

There are number of video conferencing software available and being used, but here we present the three major teleconferencing applications that are widely popular and most commonly used to conduct online classes during the lockdown.

\subsubsection{Zoom}

It is one of the most popular and largely used teleconferencing application. Zoom Meeting was created for business and not for casual or consumer use, however the company's focus to keep the product relatively simple to use as compare to its competitors; it gained immense popularity. It has become a hot new way for people to connect while social distancing during the corona virus lockdown. It recorded 200 million daily meeting participants in March 2020[6]. Zoom offers free, 40minute conference calls with up to 100 attendees. Although you can increase the time limit as well as the number of participants once you purchase a pro account. Zoom is easy to use, people don't need a login to access a meeting and the interface is relatively intuitive. People having no experience using a video conferencing app also find it easier to use zoom because of the user interface it provides. All important interfaces are right upfront. Zoom provides functions such as Audio, Video, Team Chat, Screen sharing, annotation, recording as well. The host machine is used as storage wherever necessary and no cloud platform is available. It can be used on different platforms such as Windows Linux as well as android. You can join a meeting anywhere, from any device, and access video for both internal and external communications. But recently zoom app got hampered due to security issues. Ministry of Home Affairs in India issued an advisory that the use of zoom video conferencing platform is not safe and should be avoided. Zoom 5.0 is launches with GCM encryption to overcome most of the issues. As zoom is basically viewed as a meeting app, no provision is provided for uploading assignments, creating quizzes is provided. For that purpose you need to use LMS software along with zoom. 


\subsubsection{Microsoft Team}

Microsoft promotes Teams in front of its competitors as Safe, Secure and Free. It's a part of the package Office 365. It is also acting as an up gradation from Skype, and comes with all supporting apps of Microsoft [3]. The office 365 package provides power applications as PowerPoint OneNote, Outlook as well as Forms. Teams also support for third-party apps. This acts as additional benefit for the person using Team. Team allows creating channels with different user groups, which helps in creating classes for different subjects offered by a faculty. Each channel has dedicated chat window as well where relevant post can be done as well as searched later on when needed. You can also invite more people to the chat, audio or video conferencing with @ mention. Teams provide a calendar to schedule different video lectures as per time table. This calendar also gives notifications at the time of call. Study material can also be uploaded in any format which gets stores in OneDrive and is available as and when needed. All addition functions such as recording, screen sharing, white board are supported by Team which are very helpful in conduction an online lecture. Also Teams provide the recording option available with the attendees as well which is not there in webex or in zoom. To access Team valid login credentials are needed for the organizer as well as the participants. Person having no Microsoft id will not be able to take complete benefit of Team.

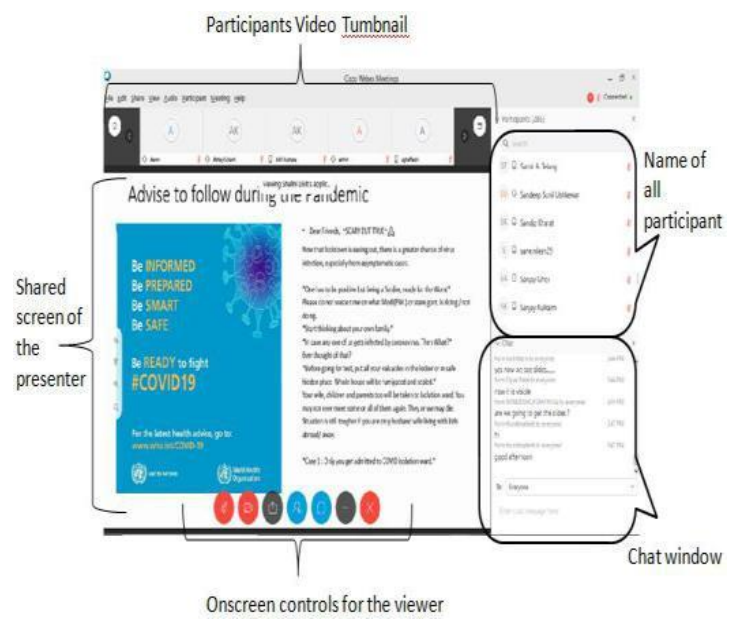

Fig 2: Webex meeting desktop screen

\subsubsection{Cisco Webex}

It's the oldest player in video conferencing software race. It has become one of the most used video conferencing tool after zoom and recorded 14 billion meeting minutes in March 2020 [6]. Webex provides one of the best audio video experiences and hence it is being used widely to conduct online training sessions and webinars. It has all the functionalities of screen sharing, recording but annotation is not directly supported. As no collaboration tools are available along with webex, it is only suitable to conduct online classes and the support of LMS software is needed for providing study material.

\subsection{Learning Management Systems}

LMS is a platform to post study materials, quizzes, assignments, discussion forums and maintain record of evaluation as well. It has also become the part of traditional education as part of ICT. LMS software go hand in hand with traditional classroom teaching and it is highly recommended. But in case of lockdown, we don't have a face to face lecture session any more. Even if there are network issues for conduction of online lectures, then the subject related material can be shared using this platform. LMS softwares are also termed as environment friendly because by usinh these platform the teachers as well as students can minimize use of paper. There are lot of options available for implementing LMS in an organization but we shortlisted the two based on popularity and ease of use-- Moodle and Google classroom.

\subsubsection{Moodle}

It is an open source learning platform developed using PHP and MYSQL; that means it is continuously being updated by hundreds of developers around the globe. It is free to download, install, use as well as modify and distribute. Moodle supports the Global Standard for Digital Course Design [7]. It can enrol thousands of students and also provide option for different languages.

\subsubsection{Google Classroom}

Google classroom is an application available on Google platform which is free to use. It comes handy with oher google apps such as Google sheets, Google forms , Calendar etc. which makes it much more useful. Teachers can take advantage of various features of Google Classrooms such as assignments, grading, communication, archive courses, mobile applications, and can measure how well students have achieved learning. With this application, students also feel motivated and active in constructing their knowledge.

\subsection{Online portals}

\subsubsection{YouTube and YouTube Live}

As YouTube is the most popular streaming platform used all over the world, it can also be a good way to deliver a lecture [5]. Recoded lectures can be uploaded on YouTube which can be viewed by not only the students of the organization but also the whole global community. The benefit is it can be watched anytime anywhere number of times. Same can be done with a Live lecture using YouTube. Facebook Live also provides a similar platform where you can invite your followers in the Live lecture.

\subsubsection{SWAYAM}

Study Webs of Active-Learning for Young Aspiring Minds. It is a program initiated by Government of India where all authentic study materials are uploaded by recognized government universities. SWAYAM platform hosts all courses from class 9 till post graduation which can be accessed by anyone, anytime, anywhere[4]. The courses are hosted in four quadrants as follows: (1) video lecture, (2) specially prepared reading material that can be downloaded/printed (3) selfassessment tests through tests and quizzes and (4) an online discussion forum for clearing the doubts. Further steps are also taken to enrich the learning experience by using audio-video, multi-media and state of the art pedagogy / technology.

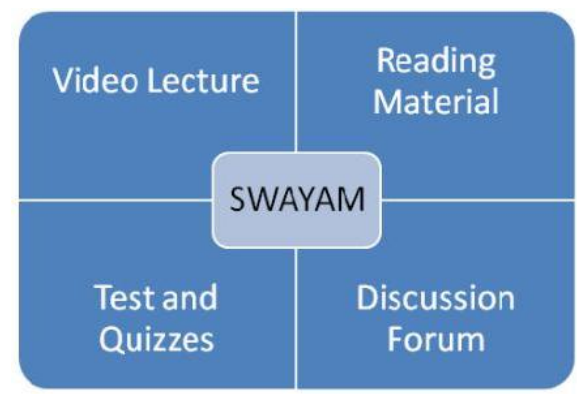

Fig 3: Four quadrants of SWAYAM

\section{SUMMARY}

For an organization running the LMS platform such as moodle or google classroom, the webex meeting might be better for 
their users and with a lower cost than if they implemented Teams for meetings. If we are only concerned about for a web meeting solution to conduct classes then Teams or Webex might not be the best, as discussed Zoom is a lot in discussions about meetings. When using Zoom or Webex, an LMS support is needed for providing study materials, quizzes and assignments. But for organizations that want chat, teleconferencing, quiz and assignments Teams will be able to solve that even if there might be other products for chat and another that is better on collaboration. Team provides all basic functions that are needed to run a smooth online education system but for a little cost. As social distancing will be here for much longer time, it's not possible to come face to face to conduct classroom teaching in near future. Hence we are left with the option of online education system which raises the need of all teaching and learning members to be aware and ready with the technologies available at hand.

\section{REFERENCES}

[1] Kyong-Jee Kim and Curtis J. Bonk. (2006) "The future of Online Teaching and Learning in Higher Education: the Survey says". Educause Quarterly.
[2] https://support.zoom.us/hc/en-us (2020) Online

[3] https://www.microsoft.com/en-in/microsoft365/microsoft-teams/free(2020) Online

[4] https://swayam.gov.in/about (2020) Online

[5] https://www.youtube.com/live_dashboard_splash Online

(2020)

[6] Mansoor Iqbal, Zoom Revenue and Usage Statistics (2020).[Online]Available:https://www.businessofapps.co m/data/zoom-statistics/. [Accessed on: 4-May-2020].

[7] Elmaghrabi \& Eljack. (2019). "Enhancement of Moodle learning Management System Regarding Quizzes Security and Stability Problems". 2nd International Conference on Computer Applications \& Information Security (ICCAIS).

[8] Rebekah Carter, Microsoft Teams vs. Zoom Comparison: Which is Right for You? (2020). [Online]Available:https://www.uctoday.com/collaboration /microsoft-teams-vs-zoom-comparison/ [Accessed on: 4May-2020] 